\title{
Noticia de un posible santuario rupestre vettón en Las Hurdes (Cáceres)
}

\author{
Saúl Martín GonZÁLeZ \\ Grupo Barbaricvm. Universidad Complutense de Madrid \\ saulmartingonzalez@yahoo.es
}

\section{RESUMEN}

A continuación se presenta una nueva "peña sacra" prerromana, asociada a un petroglifo, en la comarca de Las Hurdes (Cáceres).

Palabras clave: Petroglifo, "peña sacra", altar sacrificial, arqueoastronomía, ritos prerromanos.

\section{A New 'Sacred Stone' associated to a Petroglyph in Las Hurdes (Cáceres, Western Spain)}

\begin{abstract}
Is presented a new pre-Roman "sacred stone", in association to a petroglyph, in the Las Hurdes shire (Cáceres, Western Spain).
\end{abstract}

Key words: Petroglyph, “Sacred Stone”, Altar for Sacrifices, Archeoastronomy, Pre-Roman Rites.

\section{Breves apuntes a propósito de la comarca hurdana ${ }^{1}$}

Los trabajos arqueológicos en el marco de la comarca de Las Hurdes (Cáceres)² nos permitieron entrar en contacto con una tierra que aúna, como las dos caras de una misma moneda, una pingüe riqueza etnográfica y tradicional ${ }^{3}$ con una notable es-

${ }^{1}$ Las fotografías e imágenes que ilustran el presente artículo son siempre de factura propia, a menos que se indique expresamente lo contrario.

${ }^{2}$ En concreto, el proyecto de Seguimiento arqueológico de los trabajos de las Obras de emergencia para la mejora del abastecimiento a la comarca de Las Hurdes y declaración de urgente ocupación de los bienes y derechos afectados (Cáceres), (clave:03.310-0405/7511), ejecutada por la promotora Acciona Infraestructuras S.A. para la Confederación Hidrográfica del Tajo. Dicho seguimiento arqueológico lo dirigimos nosotros mismos a través de la empresa emeritense Anta Estudio de Arqueología, C.B, entre los meses de julio de 2010 y julio de 2011.

${ }^{3}$ Como quedó patente en los dos Congresos de Hurdanófilos, celebrados respectivamente entre el 14-15 de junio de 1908 y 11-12 de agosto de 1.988 (Iglesias Duarte, 1994, pp. 13-14), y como demuestra el calado de su música y cultura tradicional (Barroso Gutiérrez, 1991; 1994, pp. 93-126). 
casez arqueológica y patrimonial anterior a la Edad Moderna ${ }^{4}$. De las largas épocas "ágrafas" anteriores al siglo XVII ${ }^{5}$ destacan con luz propia, por encima de cualquier otro elemento, los célebres petroglifos hurdanos. La costumbre de grabar las rocas del paisaje se halla bien atestiguada en muchas épocas y culturas, suponiendo un uso ritualizado del paisaje cuya difícil interpretación, que nos llevaría lejos, se encuentra en discusión por parte de los especialistas (Harding, 2003, pp. 336 y ss.). En Las Hurdes se han identificado hasta hoy en torno a una veintena de estaciones de grabados prehistóricos, repartidos por toda la comarca. Los estudiosos han venido en general reconociendo una cronología amplia para ellos: así, la costumbre arrancaría en Las Hurdes desde algún incierto momento del Neolítico, consolidándose y desarrollándose a través de las Edades del Cobre, Bronce y Hierro, hasta desembocar en la Romanización, que lentamente iría diluyendo esta práctica a medida que los elementos mediterráneos fuesen desplazando a los indígenas (Sevillano, 1976, pp. 289$290)^{6}$. En las siguientes líneas habremos de ocuparnos de una de dichas estaciones de grabados, la conocida como El Huerto del Cura. Habremos de dar noticia de ciertos posibles elementos cultuales asociados, hasta ahora pasados por alto.

\section{El petroglifo del Huerto del Cura}

Este petroglifo, bien conocido y señalizado, se dispone en mitad del angosto valle formado por el Arroyo de Aceitunilla ${ }^{7}$, afluente del río Hurdano que nace junto a su alquería epónima, en el corazón de las montañas hurdanas. Dicho valle, que presenta un sentido Norte-Sur y una acusada sección en $\mathrm{V}$ en virtud de la acción erosiva del arroyo, encajonado entre dos líneas de montañas, supone un apéndice hacia el Norte enclavado en mitad del más amplio valle que forma el río Hurdano. En éste desagua, a la altura de Nuñomorals, aquél arroyo tras recorrer cuatro kilómetros hacia el Mediodía, transportando el agua desde el circo de montañas que separan este cauce del vecino valle del río Ladrillar (o río Malo). El petroglifo se encuentra a aproximadamente kilómetro y medio desde Nuñomoral (unos 2,5 km bajando desde Aceitunilla) junto a la desembocadura del Arroyo de la Pizarrosa en el Arroyo de Aceitunilla. En ese punto, en el margen oriental de la carretera CC-156.1, nace una vereda que tras

${ }^{4}$ Tal y como se refleja en las entradas correspondientes a sus TT.MM. en la Carta Arqueológica de Extremadura. Uno de nuestros objetivos, tanto en la documentación derivada del proyecto de Seguimiento arqueológico de obra que tuvimos ocasión de dirigir (vid. Martín González, 2011) como de la bibliografía científica que habremos de generar respecto a éste y otros trabajos, es colaborar al desarrollo y ampliación de la Carta Arqueológica.

${ }^{5}$ Épocas en las que solamente contamos con unos pocos documentos relativos a la propiedad de las tierras (Fernández Gómez, 1994, pp. 142 y ss.).

${ }^{6}$ No obstante, muchos petroglifos presentan cruces superpuestas y demás símbolos de cristianización de lugares paganos, en muchos casos adscritos de manera más o menos vaga a la Antigüedad Tardía o la Alta Edad Media. Éste es un fenómeno bien conocido en Las Hurdes, como sucede por ejemplo en la interesante estación de La Peña del Molde (Mesegal, Pinofranqueado), en El Riscal (Sauceda, Pinofranqueado) o en La Pisá de la Mora (La Huerta, Caminomorisco), además de en otras partes de Europa (Harding, 2003, p. 332).

${ }^{7}$ Imagen satelital tomada del visor del Instituto Geográfico Nacional de España.

${ }^{8}$ Cabeza del término municipal. Aceitunilla es una alquería (pedanía) de Nuñomoral. 


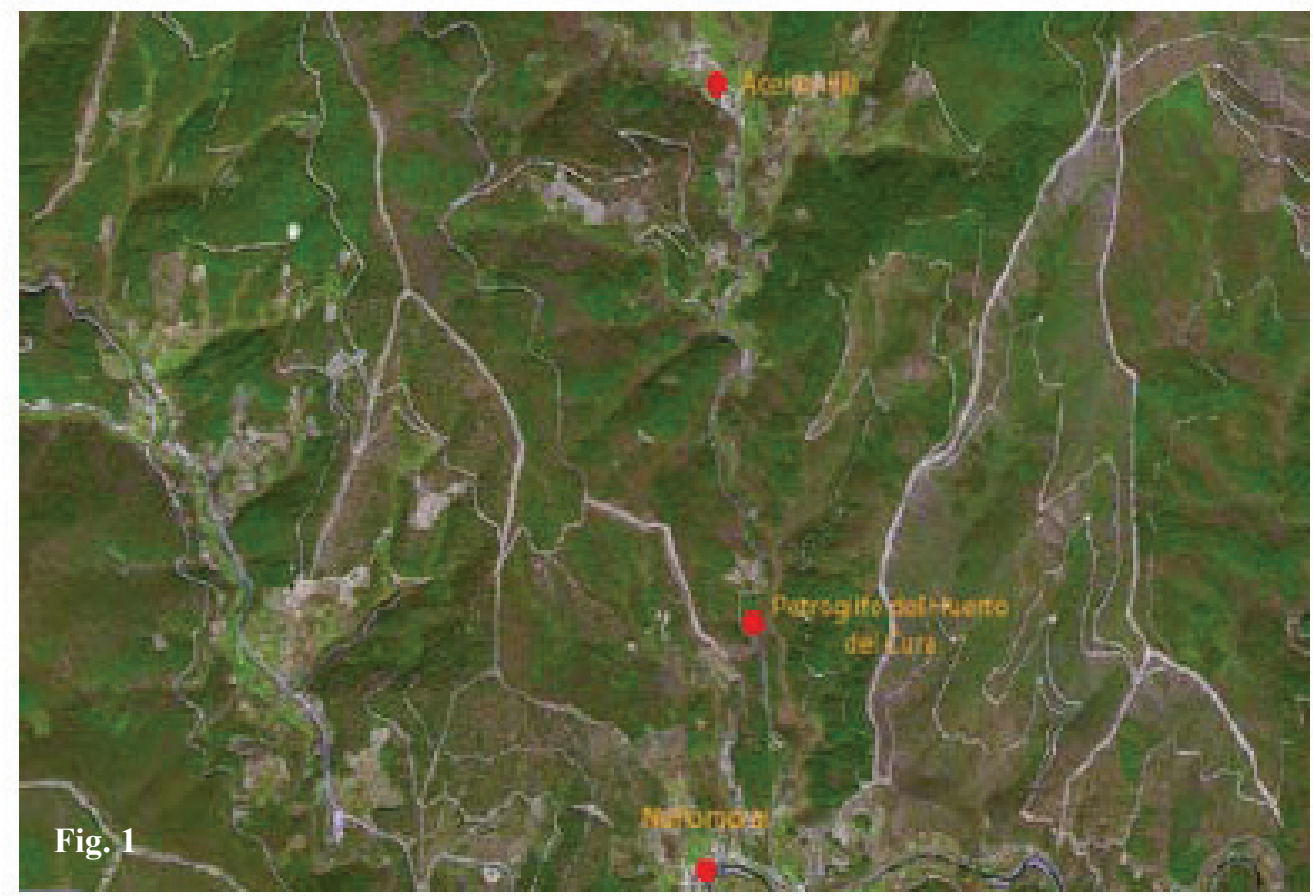

unos $150 \mathrm{~m}$. de descenso y una acusadísima diferencia de cota ${ }^{9}$ hacia la vega del Arroyo de Aceitunilla nos conduce hasta el petroglifo ${ }^{10}$, que viene practicado, al igual que otros muchos de la comarca ${ }^{11}$, sobre un afloramiento plano de la característica pizarra hurdana. Se trata de una roca enclavada a cota considerablemente más baja que la actual carretera (la versión contemporánea y pavimentada del camino tradicional de tierra que comunicaba Aceitunilla con Nuñomoral desde antiguo), dispuesta sobre el cauce hídrico, y orientada de forma casi perfecta hacia el Oriente.

En la actualidad la presente estación de grabados se encuentra convenientemente señalizada y reconocida por parte de la Administración, incluyendo sendos paneles explicativos. Ello contrasta, sin embargo, con el hecho de que se trata de uno de los petroglifos menos estudiados de la comarca hurdana, no siendo protagonista, que sepamos, de ningún estudio propio ${ }^{12}$.

${ }^{9}$ El petroglifo se encuentra a 522 m.s.n.m., mientras que la carretera CC-156.1, situada falda arriba, en este punto alcanza los 538 m.s.n.m.

${ }^{10}$ Cuyas coordenadas UTM son las siguientes: Huso 29 X: 734.039.36; Y: 4.478.216.02; situado a $522 \mathrm{~m}$ de altitud (Z) sobre el nivel medio del mar en Alicante.

${ }^{11}$ Así por ejemplo, entre otros, el de la Pisá de la Mora y el de la Piedra Mora (Caminomorisco), el del Puerto del Gamo (Casar de Palomero) o el del Lagar de la Hoya (Azabal)

${ }^{12}$ Aunque sí se recoge en la analogía de Sevillano San José (1983, p. 260) entre diversos petroglifos hurdanos respecto a los del Valle del Tajo. 


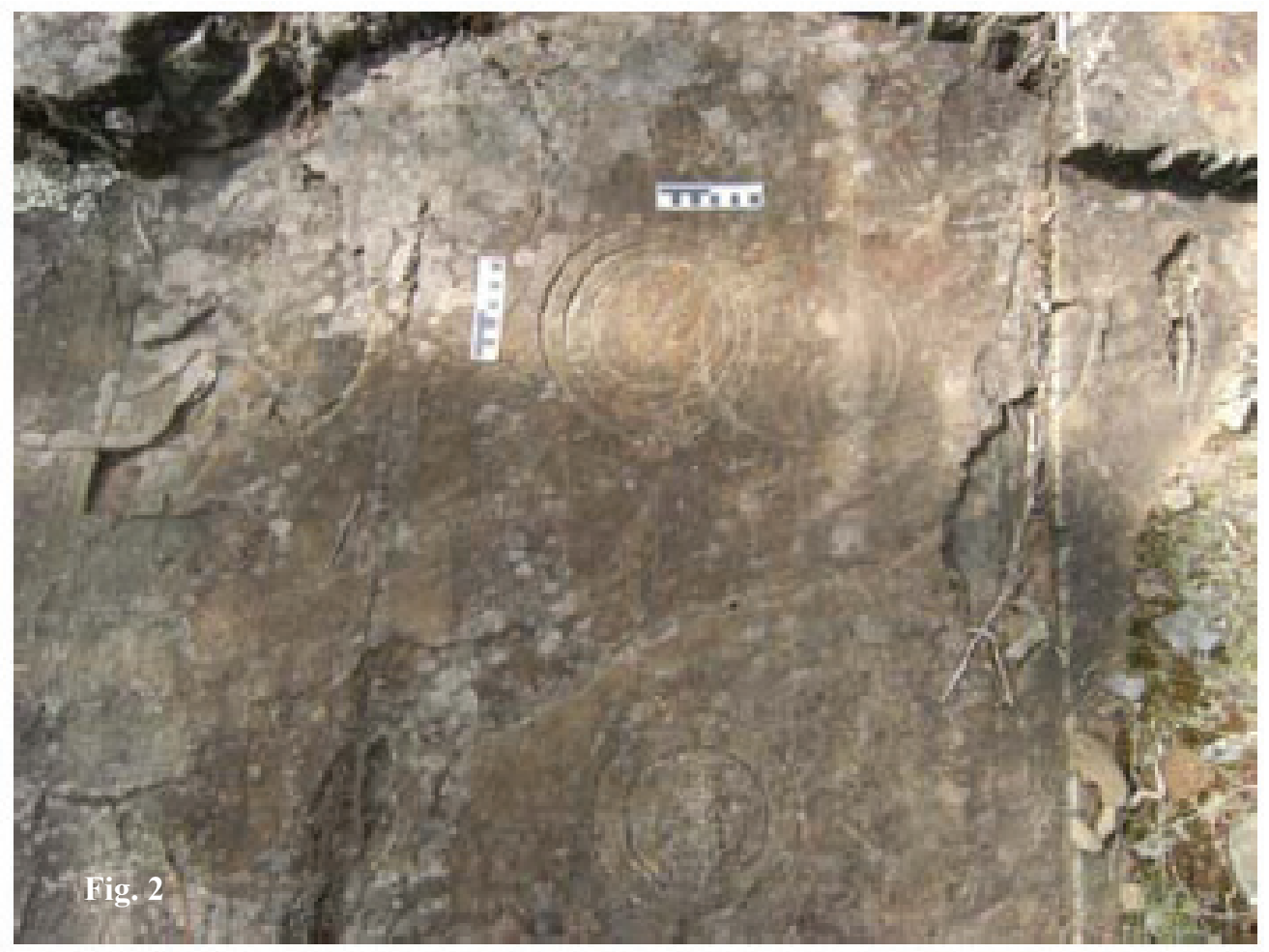

Los motivos que presenta el petroglifo son susceptibles de ser divididos en tres grupos principales:

1) Grupo I: El situado más hacia Oriente, representa dos circunferencias parcialmente unidas, además de dos circunferencias concéntricas que contienen en su interior un triángulo cuyo vértice apunta hacia el Este. El diámetro de las circunferencias ronda los $14 \mathrm{~cm}$.

2) Grupo II: El situado en el Centro, representa tres circunferencias concéntricas donde se engarza una cuarta de tamaño equivalente a la mayor de aquéllas (unos $20 \mathrm{~cm}$ de diámetro). Inmediatamente hacia Oriente respecto a ellas aparecen una serie de pequeños símbolos (una pequeña $\mathrm{X}$ y dos circunferencias de unos $4 \mathrm{~cm}$ de diámetro que parecen rellenas), mientras que hacia Occidente se dispone la primera de las estrellas de cinco puntas, contenida en una circunferencia.

3) Grupo III: El dispuesto más hacia Occidente, hasta el punto de encontrarse en el siguiente nivel de la roca, por tanto a una cota ligeramente mayor. Representa un total de tres estrellas de cinco puntas o pentalfas, dos de las cuales vienen contenidas en circunferencias, y un escaleriforme ${ }^{13}$.

${ }^{13}$ Junto a estas líneas, calco del petroglifo según Anónimo, p. 17 


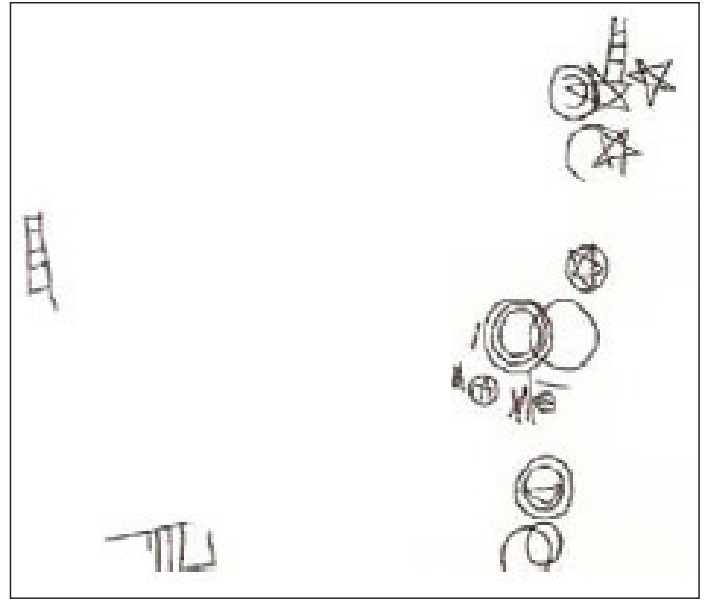

Fig. 3

Además de estos tres grandes grupos, a unos $30 \mathrm{~cm}$ hacia el Sur nos encontramos con otros dos escaleriformes independientes, separados unos $35 \mathrm{~cm}$ entre sí. Ambos símbolos vienen representados en un notable tamaño (unos $15 \mathrm{~cm}$ de longitud), y los dos presentan cinco líneas transversales que unen los dos trazos más largos. Con independencia de los signos grabados en la roca, en el ángulo sudoriental del afloramiento pizarroso donde vienen practicados éstos se documenta además una pequeña cazoleta u hornacina ovalada de $38 \mathrm{~cm}(\mathrm{X})$ por $31 \mathrm{~cm}(\mathrm{Y})$ por $11 \mathrm{~cm}(\mathrm{Z})$. Esta pequeña estructura se inunda con el agua de lluvia y el rocío y acaso pudiese haber gozado de alguna función ritual ${ }^{14}$.

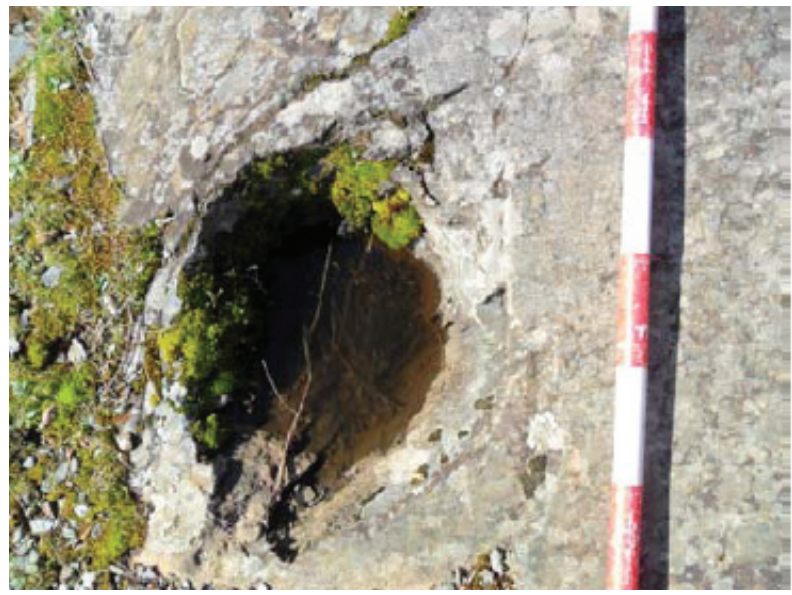

Fig. 4

${ }^{14}$ En este sentido se interpretan estos elementos, allí muy frecuentes, en El Picón de la Mora (Sánchez Nicolás; Mateos Leal y Berrocal Rangel, 2005-06, p. 162). 
Este petroglifo, tanto por su sección (en V muy apuntada ${ }^{15}$, lo que sugeriría el empleo de algún cincel o apero férreo) como por sus elementos representados ${ }^{16}$, se ha venido datando en la II Edad del Hierro.

\section{La posible "peña sacra"}

A unos 35 metros hacia el Sudeste del petroglifo, bajando ligeramente hacia la vega del Arroyo de Aceitunilla, nos encontramos con una estructura que ha venido pasando totalmente desapercibida en los escasos estudios de los que ha sido objeto la presente estación de grabados rupestres ${ }^{17}$. Dicha estructura viene practicada en uno de los abundantísimos afloramientos de pizarra maciza de los que se componen las montañas hurdanas, y de los que existen innumerables ejemplos más en derredor. No obstante, dicho afloramiento, de unos $12 \mathrm{~m}$ de longitud $(\mathrm{X})$ por 3,22 $\mathrm{m}$ de anchura (Y) por $1,98 \mathrm{~m}$ de altura $(\mathrm{Z})$, viene orientado hacia el Solis Ortus y ha sido objeto de una sutil pero innegable antropización dirigida a convertirlo en una estructura funcional, básicamente centrada en dos elementos.

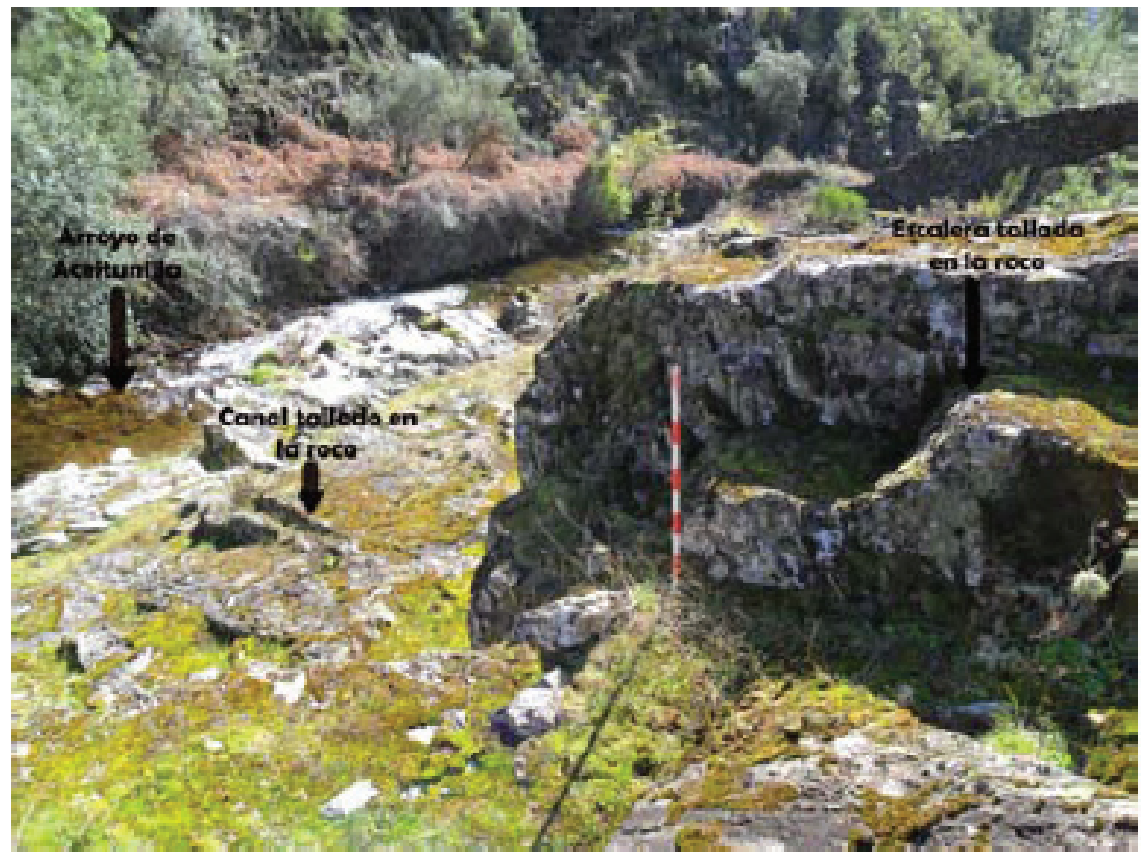

Fig. 5

${ }^{15}$ Blasco Fuerte, 2002, p. 25.

${ }^{16}$ Así aparece en la cartelería instalada in situ y en la propia "Guía de petroglifos hurdanos", Anónimo, p. 17.

${ }^{17}$ Estructura que reconocimos nosotros mismos en compañía de D. Joaquín Del Palacio, a finales de enero de 2011. 

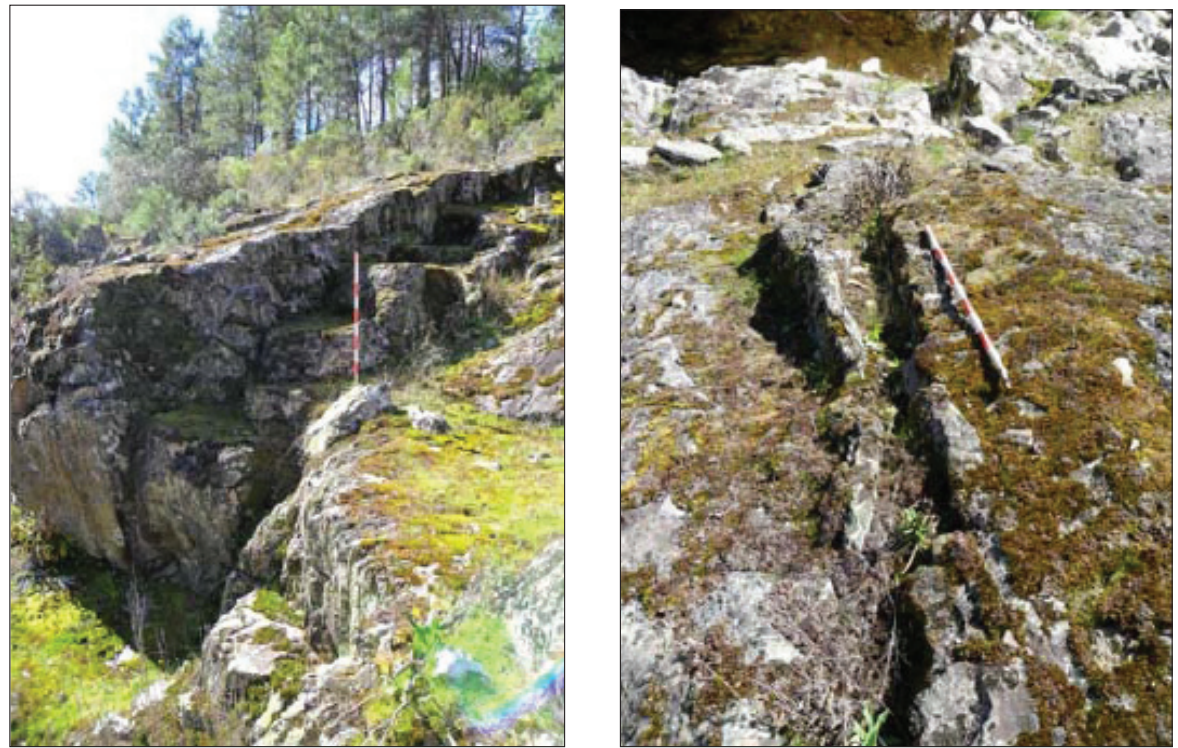

Figs. 6 y 7

El primero de ellos se dispone en el flanco septentrional de la mole. Allí se han practicado, esculpidos directamente en la roca, un total de 7 escalones de factura irregular (en general se atienen a un esquema de 90 por 90 centímetros, oscilando su altura entre los 26 y los 42 centímetros), pero en cualquier caso perfectamente alineados desde la cumbre occidental del afloramiento, situado a nivel de uso, descendiendo por el flanco septentrional de la roca hasta alcanzar prácticamente el nivel del agua. Si en lugar de bajar por las escaleras recorremos la roca hacia Oriente nos encontraremos con un saliente en voladizo, donde existe una caída de $1,98 \mathrm{~m}$ sobre el curso de agua y el segundo de los elementos referidos supra, que pasamos a detallar. Éste consiste en un canal de desagüe, de unos 3 metros de longitud (al menos, su parte conservada), por 33 centímetros de anchura (Y) y 20 de profundidad (Z), que viene, al igual que los escalones referidos supra, practicado directamente en la pizarra viva. Además, esta estructura reviste la particularidad de interconectar la mole y los escalones anteriormente referidos con el curso fluvial del Arroyo de Aceitunilla ${ }^{18}$. Además conviene recordar que nos encontramos prácticamente en el punto donde el Arroyo de la Pizarrosa (un afluente aún menor) confluye con el Aceitunilla, y como ya señalásemos supra, a $1,5 \mathrm{~km}$ río arriba de la desembocadura de éste con el principal río de esta comarca, el Hurdano. Por tanto, un lugar de triple confluencia de las aguas.

Para mejor ocasión habremos de postergar la interpretación del conjunto. Sin embargo, valga señalar el hecho de que todo parece apuntar a un espacio donde los diversos elementos antrópicos (el petroglifo y la posible peña sacra) se enmarcan a

${ }^{18}$ Un curso hídrico que cabe suponer de mayor caudal en épocas pasadas, cuando la Península presentaba una ingente masa forestal y, por tanto, un régimen de pluviosidad y un grado de humedad edafológica mucho mayores que los que conocemos en nuestros días. Sobre los análisis palinológicos del Sistema Central, vid. Franco et al., 2000. 
aquéllos naturales (el Arroyo de Aceitunilla y su valle, la orientación de éstos, los afloramientos de rocas metamórficas), que vienen en gran medida posibilitados por la orografía intrincada y accidentada del lugar. En este sentido, creemos que es preciso concebir el conjunto como un complejo sacro integrado (insistimos en este punto) que, a partir de sus distintas partes, funciona en pos de unos determinados objetivos ideológicos y supraestructurales. En los últimos tiempos se han reconocido una serie de altares rupestres y peñas sacras ${ }^{19}$, a menudo puestos en relación con el culto a las aguas, en distintos lugares del Poniente español. Además, recientemente la investigación pasa por reconocer la denominada "vía astronómica" y el estudio científico de los cielos pretéritos ${ }^{20}$. En próximos trabajos continuaremos con la interpretación de elementos como los aquí presentados.

\section{Bibliografía}

ANónimo (s.d.): Guía para conocer y visitar el arte rupestre de Las Hurdes, Diputación de Cáceres, Junta de Extremadura (Dirección General de Turismo), Ministerio de Industria, Turismo y Comercio (Secretaría General de Turismo), Fondo Europeo de Desarrollo Regional, Plan de Dinamización Turística Sierra de San Pedro-Sierra de Gata-Las Hurdes (librillo para visitantes disponible en los centros culturales y de información turística de la comarca).

Almagro Gorbea, M. - Jiménez Ávila, J. (2000): "Un altar rupestre en el Prado de Lácara (Mérida). Apuntes para la creación de un Parque Arqueológico", en J. Jiménez Ávila - J.J. Enríquez Navascués (eds.) El Megalitismo en Extremadura (Homenaje a Elías Diéguez Luengo), Extremadura Arqueológica VIII, Junta de Extremadura, Mérida, 423-442.

Barroso Gutiérrez, F.

(1991): Guía curiosa y ecológica de las Hurdes, Madrid.

(1994): "La cultura oral en Las Hurdes (romances y pliegos de cordel)", Alcántara 31-32, enero-agosto, 1994, Salamanca, 93-126.

Benito del Rey, L. - GRANDE Del Río, R. (2000): Santuarios rupestres prehistóricos en el Centro-Oeste de España, Librería Cervantes, Salamanca.

${ }^{19}$ Así, entre otros, en El Picón de la Mora en Salamanca (Sánchez Nicolás; Mateos Leal y Berrocal Rangel, 2005-06; Sánchez Nicolás y Mateos Leal, en prensa); los ocho casos propuestos por Fabián García (2010) para Extremadura y Castilla y León; los varios casos reconocidos en Zamora (Benito del Rey y Grande del Río, 2000); algún caso aislado en el Sistema Central (Almagro Gorbea y Jiménez Ávila, 2000; Canto Perea, 1994) o incluso el Mediodía extremeño hasta alcanzar la actual provincia de Huelva (Cazorla Martín y Celestino Pérez, 2008; Sánchez Nicolás; Mateos Leal y Berrocal Rangel, 2005-06; Almagro Gorbea y Jiménez Ávila, 2000). A todo ello cabría añadir quizás algunos casos aislados en Huesca (Benito del Rey y Grande del Río, 2000, p. 77), Barcelona (Almagro Gorbea y Jiménez Ávila, 2000, p. 429) y el dudoso de la "Silla de Felipe II" en El Escorial, Madrid, además de ciertos casos portugueses e irlandeses de los que habremos de ocuparnos en mejor ocasión.

${ }^{20}$ Así en Fabián García, 2010, pp. 265-266; Almagro Gorbea y Jiménez Ávila, 2000, p. 433; Sánchez Nicolás y Mateos Leal, en prensa. 
Blasco Fuerte, J. (2002): Las Hurdes. Guía turística, ADIC-HURDES, Puebla de la Calzada.

Canto Perea, A. (1994): “La 'Piedra Escrita' de Diana, en Cenicientos (Madrid) y la frontera oriental de Lusitania", CuPAUAM 21, 271-296.

Cazorla Martín, R. - Celestino Pérez, S. (2008): "La Cueva del Valle (Zalamea de la Serena, Badajoz): un santuario rupestre en la comarca de La Serena", SPAL 17, 207-231.

FABIÁN GARCíA, J.F. (2010): “Altares rupestres, peñas sacras y rocas con cazoletas. Ocho nuevos casos abulenses y uno salmantino para la estadística, el debate y la reflexión", Madrider Mitteilungen 51, 222-267.

FernÁndez Gómez, L. (1994): "Las Hurdes: de la Prehistoria a la Baja Edad Media", Alcántara 31-32, Salamanca, 137-160.

Iglesias Duarte, C. (1994): "Crónica de los Congresos de Hurdanófilos", Alcántara 31-32, enero-agosto, Salamanca, 13-34.

Martín GonzÁlez, S. (2011): Recopilación final de los trabajos de Seguimiento Arqueológico sobre las obras de abastecimiento integral de aguas a la comarca de Las Hurdes (Cáceres) (clave:03.310-0405/7511) efectuados por D. Saúl Martín González (26 de julio 2010 - 30 de junio 2011), Informe técnico depositado en la Consejería de Cultura de la Junta de Extremadura, fechado el 15 de junio de 2011.

Sánchez Nicolás, D. - Mateos Leal, C. - Berrocal Rangel, L. (2005-2006): "El santuario rupestre de El Picón de la Mora (Encinasola de los Comendadores, Salamanca)", Boletín Informativo de la Asociación Española de Amigos de la Arqueología 44, 161-180.

Sánchez Nicolás, D. - Mateos Leal, C. (e.p.): "El poblado fortificado de El Picón de la Mora: la fortificación de un paisaje sagrado en la ribera del Huebra", Actas del I Encuentro de Jóvenes Investigadores del Valle del Duero (Zamora, 16-18 noviembre 2011).

Sevillano San José, Ma Del C.

(1976): "Un petroglifo con inscripción en la comarca de Las Hurdes (Cáceres)", Zephyrus XXVI-XXVII, 269-291.

(1983): "Analogías y diferencias entre el arte rupestre de Las Hurdes y el del Valle del Tajo", Zephyrus XXXVI, 259-263. 